\title{
Is exemplification the one and only way to describe that empty set is subset of any sets?
}

\author{
Trisna Roy Pradipta ${ }^{1}$, Samsul Maarif ${ }^{1}$, Iden Rainal Ihsan², Guntur Maulana Muhammad ${ }^{3}$ \\ ${ }^{1}$ Departement of Mathematics Education, Faculty of Teacher Training \\ and Pedagogy, Universitas Muhammadiyah Prof. Dr. Hamka, Jakarta, Indonesia. \\ ${ }^{2}$ Departement of Mathematics Education, Faculty of Teacher Training \\ and Educational Sciences, Universitas Islam Nusantara, Bandung, Indonesia. \\ ${ }^{3}$ Departement of Mathematics Education, Faculty of Teacher Training \\ and Educational Sciences, Universitas Suryakancana, Cianjur, Indonesia. \\ troymath@uhamka.ac.id
}

\begin{abstract}
Various methods and techniques in mathematical proof really need to be introduced to students. Since Studying set theory, there have been opportunities in teaching mathematical proof to students. Teacher are required to choose the right methods and techniques, and be able to develop the abilities of students. A survey was conducted with teachers, lecturers, and students of mathematics education regarding opinions and explanations of how to teach proof of one of the property in set theory. It is asked how to prove that an empty set is a subset of any set. Of the 96 respondents, 69 of them though that the most appropriate way was giving an example. Based on the survey result, there also other alternatives that are relevant even for junior high school students.
\end{abstract}

Article Received: 18 October 2020, Revised: 3 November 2020, Accepted: 24 December 2020

\section{Introduction}

The ability to prove is very necessary in studying mathematics. This ability also needs to be possessed by students as early as possible. This is in line with the suggestion from [1] which states that the learning process of proof and argumentation of students is important to begin at the basic level. This can be done, is not an impossibility. Referring to the opinion from [2], [3], [4] who conveyed that deductive activitybased activities can be carried out throughout the school year in elementary school. There is even a more daring and challenging opinion, from [5] who state that evidence and argumentation can be designed in the curriculum from kindergarten to university.

Learning proof and argumentation in mathematics is not easy. Some supporting capabilities are needed in this regard. In accordance with the results of the study from [6], it is necessary to have good mathematical understanding and communication skills in overcoming student difficulties in proofing. This can be overcome by designing learning activities that can provide opportunities for students to represent and communicate their mathematical ideas, according to the research results of [7].

A teacher can choose a teaching method that is relevant to the level of development of students. Included in learning about proof. Various researches on instructional design have been carried out, one of which is from [8]. Based on the results of the research, a teacher can create a relevant learning design based on needs and context analysis. A teacher can be creative as widely as possible and freely as possible in making an instructional design. Like the research from [9], learning can be made creatively even by making an imaginary dialogue.

There are also research results that are very prominent from [10] which can be used as a reference in making learning designs about proof. Through the results of the research, which explained that there are 3 phases in the verification process, the teacher will get an overview of an instructional design that must be compiled. The three phases in question are the entry phase, the attack phase, and the review phase. It can also be referred to research from [11], which states the four mandatory stages. In that research, there are 8 stages of the teaching 
and learning process of words from the theorem, namely, determining the form of the statement; selecting the explanations, hypotheses, and conclusions; make a short note of the theorem; and wording the theorem "in its own way".

In this article, we will explore perspectives on techniques in conveying evidence. In this case it is related to the proof regarding the empty set. The principles that we refer to are the results of studies from [12]. Teachers need to provide guidance to equip students with the necessary resources so that they can effectively generate evidence and evidence among students.

\section{Methodology}

Participants

This study is a discussion and analysis of the results of a survey conducted in online mode via google form. Respondents in this survey were teachers, lecturers, and mathematics education students (some of whom have participated in practical teaching programs/teaching internship). As for the number of respondents is 96 people. In general, respondents live in the provinces of West Java and Jakarta. Following is the distribution of respondents' domicile

Table 1. Respondent data based on domicile.

\begin{tabular}{lc}
\hline City & Number of Respondents \\
\hline Bandung & 26 \\
Bekasi & 2 \\
Bogor & 1 \\
Cianjur & 30 \\
Ciamis & 2 \\
Cimahi & 1 \\
Cirebon & 2 \\
Depok & 2 \\
Garut & 1 \\
Jakarta & 22 \\
Majalengka & 1 \\
Sumedang & 1 \\
Tasikmalaya & 1 \\
Other (outside Jakarta and West Java) & 4 \\
\hline
\end{tabular}

Based on occupation, here is the proportion of teachers, lecturers, and students

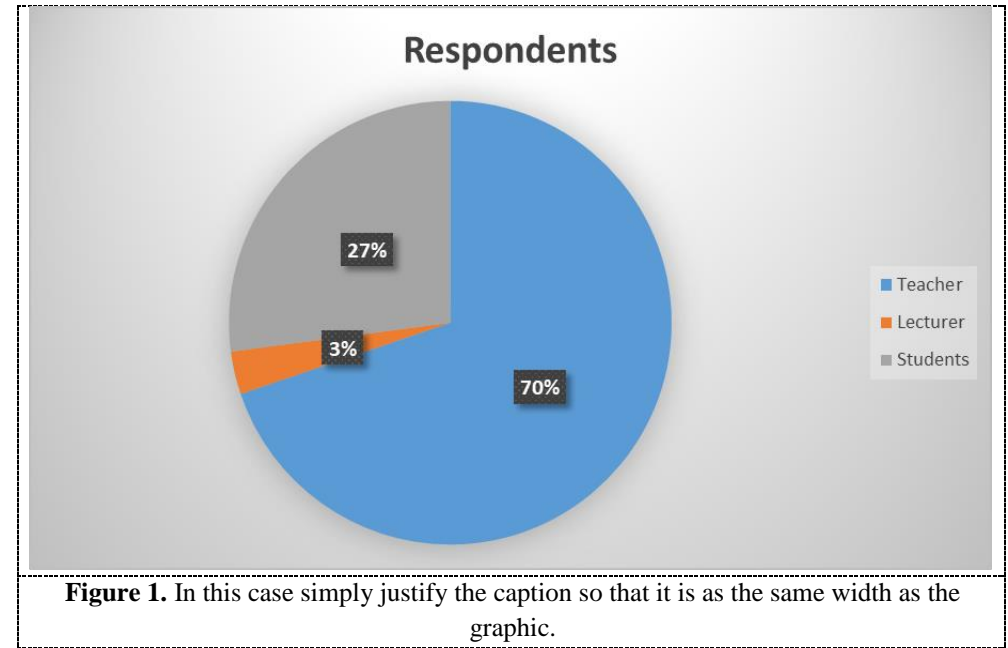

\section{Materials}


In the survey questions were asked about how and techniques to convey proof of the statement "an empty set is a subset of any set". We analyze all the alternative answers given regarding the suitability of the answer descriptions and their relevance to the student's level. We make connections between alternative methods of explanation and the level of student development. This result is what we will use in needs and contexts analysis for preliminary research purposes like research from [12]

\section{Results and findings}

In this article, a recapitulation of alternative answers from respondents was generated. We present a recapitulation in the result subsection. We also present findings in the form of alternative answers that we succeeded in exploring from the survey results.

\section{Respondents' perceptions}

After we analyzed the survey data, it was found that approximately 72 percent of respondents chose (answered) exemplification. These results are consistent with and support the research results of [14] which stated that teachers will continue to use examples in teaching their students, where examples can be the main means of learning mathematical concepts. Almost every respondent who is a teacher selected exemplification.

\section{Alternatives perceptions}

We also carry out tracing and assessment of the responses obtained. Apart from giving examples, there are other alternatives in explaining this empty set problem. Three alternative evidentiary delivery techniques are classified in terms of our question.

The first alternative, a combinatorics approach can be selected. At first it was like giving an example, but not just an example without giving students the opportunity to find concepts. Students are directed to think abstractly, but starting from simple things. We strongly agree that this scenario can be presented for junior high school students. At the beginning, students are given the opportunity to think inductively by asking about how many subsets is owned by a set that has finite members, for example 3. Students are then asked why there are 8 subsets. Students are directed to understand that in counting all the existing subsets, each member of the set has two possibilities, called or not. Thus there is a possibility that all members are not mentioned which results in the subset that is built having no members at all. In this article, we will explore perspectives on techniques in conveying evidence. In this case it is related to the proof regarding the empty set. This thinking process is in accordance with the research results of [13] and [15] regarding the four levels in combinatorial thinking.

Two other alternatives that we have successfully explored generally have to do with the logic of implications. The statement "each empty set is a subset of any set" can be converted into the statement " $x \in \emptyset \Rightarrow x \in A$ ", where $\mathrm{A}$ is any set. Statement " $x \in \emptyset "$ is always wrong, because empty set has no member. So, regardless of whether statement " $x \in A$ " is true or false, statement $" x \in \emptyset \Rightarrow x \in A "$ is always true. Although it is less relevant to the thinking of junior high school students, this technique can be chosen to be used in teaching proof.

Another alternative to implications is indirect proof [16][17]. We can make the negation of the statement to be proved, i.e " $\varnothing$ is not a subset of $A$ ". As a result there must be at least one member of $\varnothing$ which is not member of $A$. It is a false statement, and thus the negation is false.

\section{Conclusions}

Based on our findings, it can be concluded that most teachers prefer the exemplification. This is due to its simplicity and practicality. According to [18], it is possible that teachers do not learn about evidence themselves or do not realize the importance of teaching reasoning. This could be a needs analysis for research in mathematics education. It is very important to deepen learning about logic, because exemplification is not the only way. No less important is the ability of combinatorial thinking [13] [15], which in fact can be used as an alternative in teaching evidence in this case. We must also pay attention to the two 
domains of evidentiary ability, namely proof construction and proof comprehension [19].

\section{References}

[1] T. G. Campbell, J.D. Boyle, and S. King, "Proof and argumentation in K-12 mathematics: a review of conceptions, content, and support", International Journal of Mathematical Education in Science and Technology, vol. 51, issue 5, pp. 2020, doi:10.1080/0020739X.2019.1626503

[2] S. Cyr, "Development of beginning skills in proving and proof writing by elementary school students", Proceedings of the Seventh Congress of the European Society for Research in Mathematics Education, pp. 263-272, 2011.

[3] M. Pericleous, "The role of defining in pre-proving activity,......

[4] M. Pericleous and D. Pratt, "The and preproving in the primary classroom,......

[5] V. Durand-Guerrier, K. Hemmi, N. Jahnke, and B. Pedemonte, "Introduction to the papers pf WG 1 : argumentation and proof", Proceedings of the Seventh Congress of the European Society for Research in Mathematics Education, pp. 93-98, 2011.

[6] E. Salsabila, "Influence of prerequisite concepts understanding and mathematical communication skills toward student's mathematical proving ability. PYTHAGORAS: Jurnal Pendidikan Matematika, vol. 14, no.1, pp. 46-55, 2019 doi: https://doi.org/10.21831/pg.v14i1.25067

[7] L. Zhe, "Survey of primary students' mathematical representation status and study on the teaching model of mathematical representattion", Journal of Mathematics Education, vol. 5, no. 1, pp. 66-76, 2012.

[8] T. Plomp, "Educational design research : an introduction", ed T. Plomp and N. Nieveen, Educational design research part a : an introduction (pp. 10-51).
Enschede :Netherlands Institute for Curriculum Development (SLO), 2013.

[9] C. Brodahl and U. Wathne, "Imaginary dialogues : in-services teachers' steps towards mathematical argumentation in classroom discourse, JISTE: Journal of the International Society for Teacher Education, vol. 22, issue. 1, pp. 30-42, 2018

[10] F. Hakim and Murtafiah, "Students' thinking process in solving mathematical proof problem", Matematika dan Pembelajaran, vol. 8, no. 1, pp. 12-26, 2020 , doi http://dx.doi.org/10.33477/mp.v8i1.1251

[11] N. Tarasenkova, I. Akulenko, K. Hnezdilova, and I. Lovyanova, "Challenges and prospective directions of enhancing teaching mathematics theorems in school", Universal Journal of Educational Research, vol.7, no.12, pp. 2584-2596, 2019, doi 10.13189/ujer.2019.071205

[12] A.J. Stylianides, "Proof and proving in school mathematics", Journal for Research in Mathematics Education, vol. 38, no.3, pp. 289-321.

[13] I.R. Ihsan and N. Karjanto, "Optimizing students combinatorial thinking skill through design-based research", Presented at International Congress on Industrial and Applied Mathematics 2019 at Universitat de Valencia, 15-19 July 2019.

[14] L.K. Ng and J. Dindyal, "Examples in the teaching of mathematics : teachers' perceptions,....

[15] M. Rezaie and Z. Gooya, "What do I mean by combinatorial thinking?"

[16] S. Antonini and M.A Mariotti, "Indirect proof: what is specific to this way of proving?, ZDM Mathematics Education, vol 40, pp. 401-412, 2008, doi : 10.1007/s11858-008-0091-2

[17] D. R. Thompson, "Learning and teaching indirect proof", ,.....

[18] U. Wathne and C. Brodahl, "Engaging 
mathematical reasoning-and-proving: a task, a method, and a taxonomy", JISTE: Journal of the International Society for Teacher Education, vol. 23, issue. 1, pp. 617, 2019

[19] M. Waluyo, T. Vidakovich, N. Ishartono, and M. Toyib, "A review of assessing mathematical proving ability". 